\title{
A new metabolic muscle disease due to abnormal hexokinase activity
}

\author{
K R POULTON, S NIGHTINGALE \\ From the Midland Centre for Neurosurgery and Neurology, Smethwick, West Midlands, UK
}

SUMMARY A 34 year old man presented with an 8 year history of mild muscle pain and stiffness on exertion especially in the cold. Clinical examination was normal. Apart from a mild persistent leucocytosis, his routine investigations were normal including creatine kinase activity, electromyography and nerve conduction studies. An ischaemic exercise test produced a slow and incomplete rise in lactate. Histological examination showed non-specific myopathic changes in some quadriceps femoris muscle fibres. Investigation of muscle metabolism by spectrofluorometric analysis of muscle enzyme activity and by muscle fibre incubation studies revealed a severe defect in glucose phosphorylation, associated with an electrophoretically abnormal hexokinase. Further metabolic studies suggest that the block in glucose metabolism is by-passed via an enhanced phosphorylation of fructose by the abnormal hexokinase.

Hexokinase (HK) (ATP: D-hexose-6-phosphotransferase: EC 2.7.1.1) has an important role in glucose metabolism in skeletal muscle, catalysing the phosphorylation of a number of hexoses to their respective 6-phosphates as they enter the sarcoplasm. Four different isoenzymes of $\mathrm{HK}$ have been isolated. ${ }^{1-4}$ Insulin sensitive tissues, and hence skeletal muscle, have mainly HKII (electrophoretic nomenclature) which has a $\mathrm{Km}$ for glucose of $10^{-4} \mathrm{M}^{1}$ which is considerably lower than the $\mathrm{Km}$ for fructose. ${ }^{2}$ Three other HK isoenzymes (HKI, HKIII and HKIV) exist in human tissues with differing kinetic properties and electrophoretic mobilities. ${ }^{134}$ HKIV is also known as glucokinase; it has a $\mathrm{Km}$ of $10^{-2} \mathrm{M}$ for glucose and is exclusively a liver enzyme. HKI is mainly associated with brain, but varying amounts of HKI, HKII and HKIII exist in most tissues.

A specific system for phosphorylation of fructose exists in liver by means of ketohexokinase (KHK) (ATP: D-fructose-1-phosphotransferase: E.C. 2.7.1.3), ${ }^{56}$ the products being directed towards lipogenesis rather than anaerobic metabolism. Skeletal muscle has a level of KHK so low as to be

Address for reprint requests: Dr S Nightingale, Midland Centre for Neurosurgery and Neurology, Smethwick, Warley, West Midlands, B67 7JK, UK.

Received 6 February 1987 and in revised form 3 June 1987. Accepted 8 June 1987 regarded as negligible. However, enzyme mea- $\frac{\curvearrowright}{\varnothing}$ surements in muscle from patients with the X-linked muscular dystrophies (Duchenne and Becker) have shown higher activity of both KHK and fructose-1phosphate splitting aldolase than in normal subjects. ${ }^{7}$ Electrophoretic separations of $\mathrm{HK}$ isoenzymes ince muscle from patients with Duchenne and Becker mus-? cular dystrophies has shown an abnormality of HKII with increased mobility towards the anode. ${ }^{48}$

We report the case of a man with no detectable glucose phosphorylating activity in his skeletal muscle and abnormal HK electrophoretic mobility. In view of our previous studies in X-linked muscular dystrophy patients, an investigation of his muscle's fructose metabolism was undertaken in order to discover if metabolic compensation to the enzyme deficiency has occurred.

\section{Casé report \\ Clinical features \\ A 34 year old male unemployed labourer was admitted in 1985. He had been well until 8 years previously when he had developed intermittent sharp pains in the region of his right knee, which were worse with walking one and a half miles $(2.4 \mathrm{~km})$ or in cold weather. These symptoms remained unchanged until 18 months before admission when he had developed similar pains in the left knee, as well as a constant "heavy" feeling across the back of his neck. All of these symptoms were worse as soon as he commenced any exer- tion and also in cold weather. He had no "second-wind phe-}


nomenon", which is to say that the symptoms did not lessen when exertion was continued. He denied weakness of the muscles even when the symptoms were severe, but with continued exertion his muscles seemed "stiff" and his walking became "awkward", so that he would, for example, have some difficulty climbing stairs. For 6 months, he had experienced painful nocturnal calf cramps about twice a week and rarely when resting during the day. His symptoms were not related to eating or alcohol ingestion. He had not noticed urine colour change after exertion, nor had the muscles been tender to palpation. He had no symptoms to suggest involvement of the extraocular, facial or bulbar muscles.

Prior to these symptoms he had been well. His birth had been normal and, although not keen on sport, he had been normally active in his early life and teens. There had been no apparent change in his life style, diet or general health to account for the onset of muscle symptoms in the last few years.

He had three brothers (including a non-identical twin) and two sisters who were all well, as were his parents (unrelated to one another), two sons (age 11 and 5 years) and a daughter (13 years). There was no family history of muscular or neurological disease.

Examination revealed a short, well built man of normal somatotype (height $=1.58 \mathrm{~m}$; weight $=65.7 \mathrm{~kg}$ ), with no muscle wasting, fasciculation or focal muscle hypertrophy. The muscles were firm to palpation, though not excessively, and were not tender. A brief percussion myotonia could be elicited over the deltoid muscle or thenar eminence, but no myotonia was observed following voluntary contraction. Muscle tone, power and reflexes were normal in all limbs and his plantar responses were flexor. His gait was normal and he could jump up from the squatting position or hop on either leg without difficulty. Examination of his mental function, cranial nerves, coordination and sensation were normal. General examination of his respiratory, cardiovascular, and abdominal systems were normal. He had a faint purple reticular mottling over the legs but no skin lesions elsewhere and no lymphadenopathy. Brisk walking in a cold environment caused him to complain of "tightness" of the leg muscles and the back of the neck, but re-examination revealed no abnormal signs, though he experienced the sensation of further tightness of the muscles during maximal effort. The muscle symptoms persisted for several hours before gradually resolving.

\section{Investigations}

The white blood cell count was persistently mildly elevated at between 10 and $16 \times 10^{9} 1^{-1}$ (neutrophils $81 \%$, lymphocytes $16 \%$, eosinophils $1 \%$, basophils $1 \%$, monocytes $1 \%$ ), but haemoglobin, red blood cell indices, platelet count and blood film were normal. The following serum or plasma concentrations were normal: urea, electrolytes, bilirubin, alkaline phosphatase, aspartate transaminase, gamma glutamyl transferase, albumin, globulin, glucose, calcium, phosphate, free thyroxine and creatine kinase. The rheumatoid latex test, direct Coomb's test, antinuclear factor, and antibodies to mitochondria and smooth muscle were all negative. Electromyography was performed in the right abductor pollicis brevis, abductor digiti minimi, biceps, deltoid, extensor digitorum brevis, quadriceps femoris, tibialis anterior and gas- trocnemius. No spontaneous activity was recorded in these muscles and the interference patterns were complete. Motor unit potentials were of normal configuration and amplitude, though some polyphasic potentials were seen in the tibialis anterior and gastrocnemius with maximum amplitudes of 3-4 $\mathrm{mV}$ and less frequently in quadriceps femoris too. Motor and sensory conduction velocities were normal in the right median, ulnar, lateral popliteal, tibial and sural nerves. F-wave latencies of the right median, ulnar and tibial nerves were normal. Ischaemic exercise of the right lower leg for 3 minutes did not provoke muscle spasm. Repetitive stimulation of the right lateral popliteal nerve at a rate of $20 \mathrm{~s}^{-1}$ resulted in physiological increment in extensor digitorum brevis. The electromyogram of the biceps muscle was repeated following exposure to a cold environment, but the electromyogram appearance was not altered.

\section{Methods}

\section{Ischaemic exercise test}

Ischaemic exercise ${ }^{1421}$ was carried out on the patient using a modification of the technique devised in this laboratory (A. L. Woolf, personal communication). The patient is fasted for 12 hours and confined to bed for 30 minutes before the test. The patient's forearm is made ischaemic with a cuff round the upper arm inflated to $180 \mathrm{~mm} \mathrm{Hg}$ and a wrist cuff to $80 \mathrm{~mm} \mathrm{Hg}$. After a base line blood sample, exercise in the form of rapid and vigorous squeezing of an elastic bandage for 45 seconds is followed by 1 minute rest. The biceps cuff is then released and blood sampled every $30 \mathrm{sec}$ onds for 10 minutes and assayed for lactate (BCL Ltd kit adapted for operation on a Cobas Bio centrifugal analyser, Roche Diagnostica)

\section{Enzyme determination}

Ketohexokinase, hexokinase and fructokinase (ATP: DFructose-6-phosphotransferase E.C. 2.7.1.4.) were assayed by similar spectrofluorometric methods designed to avoid interference from endogenous substrates. About $50 \mathrm{mg}$ of muscle was pulverised in liquid nitrogen and extracted into 20 volumes of ice-cold buffer $(20 \mathrm{mM}$ Tris, $50 \mathrm{mM} \mathrm{KCl}$, $0.5 \mathrm{mM}$ EDTA, $0.5 \mathrm{mM}$ phenylmethylsulphonyl, fluoride, $0.5 \mathrm{mM}$ dithiothreitol: $\mathrm{pH} \mathrm{7.4)}$. After thawing and centrifuging at $4,500 \mathrm{~g}$ at $4^{\circ} \mathrm{C}$ for 10 minutes the supernatant was divided into two portions of known volume. One portion was subject to gel filtration on a Sephadex G-25 column (column dimensions $0.9 \times 15.5 \mathrm{~cm}$ ) with $0.4 \mathrm{M}$ triethanolamine: $\mathrm{pH} 7.5$ as elution buffer. The protein peak was detected by an LKB Uvicord and collected; the volume was then measured. The other aliquot of extract supernatant was used without further treatment.

(1) Hexokinase activity $20 \mu \mathrm{l}$ untreated extract was drawn into a flow cell containing $0.5 \mathrm{mg} / \mathrm{ml}$ NADP, $0.5 \mathrm{mg} / \mathrm{ml}$ ATP, $0.01 \%(w / v) ~ \mathrm{MgCl}_{2}, 1 \mathrm{U}$ glucose-6-phosphate dehydrogenase (G6PDH) (BCL Ltd) made up to $200 \mu$ l with $0.4 \mathrm{M}$ triethanolamine: $\mathrm{pH} 7.5$. The reaction was started with $10 \mu \mathrm{l}$ of $10 \mathrm{mM}$ glucose and the rate of NADPH formation observed as the increase in fluorescence followed in an MPF3 spectrofluorimeter (Perkin Elmer). 
(2) Ketohexokinase activity $100 \mu \mathrm{l}$ of desalted extract was drawn into a flow cell containing $0.5 \mathrm{mg} / \mathrm{ml} \mathrm{ATP,} 0.01 \%$ (w/v) $\mathrm{MgCl}_{2}, 50 \mathrm{mM} \mathrm{KCl}, 10 \mu \mathrm{M} \mathrm{NaF}, 2 \mathrm{mg} / \mathrm{ml} \mathrm{NADH}$ and $100 \mathrm{U}$ triosephosphate isomerase, $90 \mathrm{U}$ fructose-1phosphate splitting aldolase and $3 \mathrm{U}$ glycerol-3-phosphate dehydrogenase made up to $200 \mu \mathrm{l}$ with $0.4 \mathrm{M}$ triethanolamine: $\mathrm{pH} 7 \cdot 5$. The reaction was started with $10 \mu \mathrm{l}$ of $10 \mathrm{mM}$ tagatose and the oxidation of NADH followed spectrofluorometrically. This procedure kept the concentration of tagatose below the $\mathrm{Km}$ for fructose of hexokinase and provided a high concentration of $\mathrm{KCl}$ to stimulate $\mathrm{KHK}$.

(3) Fructokinase activity $100 \mu \mathrm{l}$ of desalted extract was assayed in $0.5 \mathrm{mg} / \mathrm{ml} \mathrm{NADP,} 0.5 \mathrm{mg} / \mathrm{ml} \mathrm{ATP,} 0.01 \%(\mathrm{w} / \mathrm{v})$ $\mathrm{MgCl}_{2}$ with $1 \mathrm{U}$ each of G6PDH and phosphoglucose isomerase. The reaction was started with $10 \mu \mathrm{l}$ of $0.5 \mathrm{M}$ fructose and the reduction of NADP. followed spectrofluorometrically.

Incubation experiments Muscle specimens were placed on ice immediately after their surgical removal and kept moist with Krebs-Ringer Phosphate (KRP). ${ }^{15}$ Fibre bundles were dissected out ${ }^{16}$ and between 30 and $50 \mathrm{mg}$ transferred to $1 \mathrm{ml}$ KRP in the main compartments of Warburg flasks kept on ice. Radiotracer substrates of $10-25 \mu \mathrm{Ci}$ were introduced into the flask's side arms which were then stoppered. In the centre well were placed two 2-ply fibreglass filter discs (Whatman GF/A $2.1 \mathrm{~cm}$ diameter) soaked in $200 \mu 11 \%(\mathrm{v} / \mathrm{v})$ 2-methoxyethylamine. The flasks were then transferred to a shaking water bath and allowed to equilibrate at $37^{\circ} \mathrm{C}$. The main stopper was then put in place and the contents of the side arm tipped in. Incubation of the muscle was carried out for 60 minutes after which time the fibre bundles were removed, washed, blotted and pulverised in liquid nitrogen and extracted into $1 \mathrm{ml} 30 \%(\mathrm{w} / \mathrm{v}) \mathrm{KOH}$ containing $10 \mathrm{mg} / \mathrm{ml}$ glycogen. Glycogen was prepared from this extract by a triple ethanol-precipitation/water-resolvation cycle ${ }^{17}$ and the final pellet redissolved in $1 \mathrm{ml} \mathrm{H}_{2} \mathrm{O}$ and subjected to liquid scintillation counting using NE260 as cocktail (Nuclear Enterprises).

The wicks soaked in methoxyethylamine were recovered and the centre well washed three times with methanol. The wicks together with the washings were dispersed in $10 \mathrm{ml}$ NE260 and then counted for beta emission.

Lactate and sorbitol were measured in the incubation media remaining in the Warburg flasks by the method of Bergmeyer $^{18}$ adapted for automation onto a Cobas Bio centrifugal analyser (Roche Diagnostica).

Glycogen level Muscle stored glycogen was measured by digestion of glycogen in a muscle homogenate with Amylo 1,$6 ; 1,4$ glucosidase (Aspergillus Sp.) at $55^{\circ} \mathrm{C}^{17}$ and the resulting free glucose assayed by Glucose Rapid II Kit method (Roche) on a Cobas Bio centrifugal analyserRoche Diagnositca.

Electrophoresis Tissue samples $(50-100 \mathrm{mg})$ were homogenised in 10 volumes of ice-cold $0.1 \mathrm{M}$ Tris: $\mathrm{pH} 7.4$ containing $5 \mathrm{mM}$ EDTA and $10 \mu \mathrm{M}$ glucose. Homogenates were centrifuged at $25,000 \mathrm{~g}$ for 60 minutes at $4^{\circ} \mathrm{C}$. Supernatants were then concentrated five fold in Minicon Polymer blocks (Amicon Ltd) and applied directly onto cellogel strips
(Reeve Angel) for electrophoresis at $200 \mathrm{~V}$ for 1 hour in $0.04 \mathrm{M}$ sodium barbital buffer: $\mathrm{pH} 8.4$ containing $2.7 \mathrm{mM}$ EDTA at $4^{\circ} \mathrm{C}$.

Staining for hexokinase took place using an agar gel modification of the thiozolyol blue-oøupled enzymic stain ${ }^{19}$ at three different glucose concentrations. $375 \mathrm{mg}$ of agarose was dissolved in $50 \mathrm{ml} 0.1 \mathrm{M}$ Tris: $\mathrm{pH} 8.0$ buffer. at $100^{\circ} \mathrm{C}$ and then cooled to $45^{\circ} \mathrm{C}$. Gel strips were immersed in agarose/Tris matrix containing $10 \mathrm{mM}$ or $0.5 \mathrm{mM}$ or $10 \mu \mathrm{M}$ glucose, $20 \mu \mathrm{M} \mathrm{MgCl}_{2}, 0.5 \mathrm{mg} / \mathrm{ml} \mathrm{ATP}, 0.3 \mathrm{mg} / \mathrm{ml} \mathrm{NADP}$ $0.12 \mathrm{mg} / \mathrm{ml}$ phenozenemethosulphate and $0.12 \mathrm{mg} / \mathrm{ml}$ thiozolyol blue and $80 \mathrm{U} \mathrm{G6PDH}$, and incubated at $37^{\circ} \mathrm{C}$ for 1 hour to allow permeation of stain into the gel and then incubated overnight at $4^{\circ} \mathrm{C}$ (both stages being carried out in the dark). The agarose prevented the background from staining too swiftly and significantly slowed the fading of the bands when exposed to light.

\section{Results}

\section{Histology}

Paraffin sections of the left quadriceps femoris muscle obtained from open biopsy showed an abnormal variation in muscle fibre size from moderate atrophy to slight hypertrophy with some replacement by fat and fibrosis, but no collections of lymphocytes, necrotic fibres or regenerating fibres. There was no excess of internal nuclei. One nerve was seen at the edge of thec specimen which showed a minor excess of fibrosis and loss of myelinated axons. The cryostat sections showed similar morphological features. The fibre type differentiation was possible on the neutral fat (Sudano Black) and glycogen (PAS) stains though there was anexcess of neutral lipid and PAS in some fibres. There was a good phosphorylase reaction with fibre type differentiation though some fibres showed reduced activity. NADH showed good fibre type differentiation, though there were some groups of very small type I fibres and a few fibres showed a patchy reduction in reactivity. The ATP stain showed a similar fibre type distribution to NADH. Electronmicroscopy showed gross disruption in a few of the sampled fibres with focal loss of sarcomeres leaving sarcoplasm-containing lipid droplets and some glycogen. Elsewhere there was partial loss of fibrillary protein. Some fibres showed differential contraction and others showed distortion of the banding pattern with smearing and discontinuity of $\mathrm{Z}$ bands in places and reduction and discontinuity of I bands elsewhere. Dilatation and reduplication of the sarcoplasmic reticulum and $T$ system triads were conspicuous, with focal honeycomb-like proliferation of packed $\mathrm{T}$ system tubules. The mitochondria were normal.

\section{Ischaemic exercise test}

The patient exercised continuously for the full 45 second test period. The blood lactate gradually rose to a peak level of $2.48 \mathrm{mmol} / \mathrm{l}$ at about 4 minutes after 


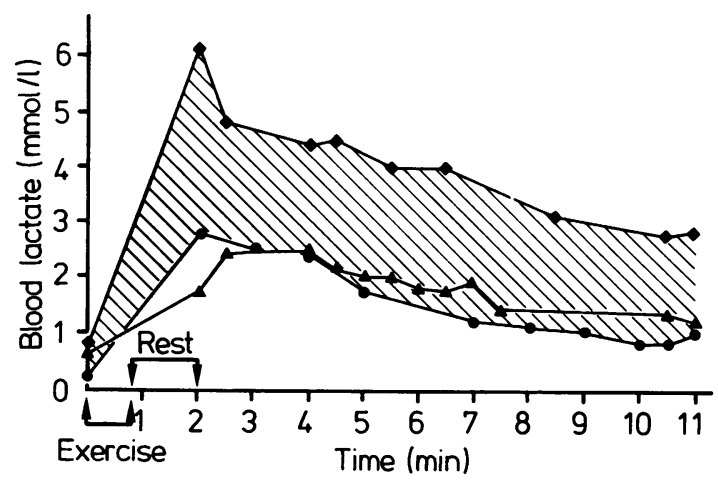

Fig 1 Plot of blood lactate levels in the patient during ischaemic exercise. The shaded area is the normal range ( $2 S D$ from the mean) from five subjects, three of whom had muscle weakness not due to a metabolic fault and two were healthy controls.

the start of the exercise period. This represents a 3.75 fold increase in blood lactate from the base line sample. The test results are displayed in fig 1 . Ischaemic exercise lactate curves from healthy individuals and patients presenting with non-metabolic causes of muscle weakness usually show a three to four fold increase in lactate within 1 minute of the end of exercise.

\section{Enzyme assays}

Table 1 shows enzyme activity and glycogen measurements. The muscle was also assayed for phosphofructokinase, phosphorylase, phosphorylase kinase, acid and neutral maltases, phosphoglucomutase, phosphoglucose isomerase, both fructose-1phosphate splitting and fructose 1,6 bis phosphate splitting actions of aldolase, debrancher enzymes and carnitine palmitoyl transferase, all of which had activities within the range expected for normal muscle. Muscle glycogen measurements were normal. The ability to phosphorylate glucose to glucose-6phosphate was not detectable in this muscle, even

Table 1 Muscle enzyme and glycogen determinations

\begin{tabular}{llll}
\hline Measurement & Patient & $\begin{array}{l}\text { Normal subject } \\
\text { range }(N)\end{array}$ & $\begin{array}{l}\text { Dystrophic subject } \\
\text { range }(N=9)\end{array}$ \\
\hline Hexokinase & ND & $0.12-0.98(88)$ & $0.15-0.93$ \\
Fructokinase & 0.554 & $0.01-0.10(19)$ & $0.01-0.13$ \\
Ketohexokinase & 0.04 & $0.0-0.6(54)$ & $1.5-11.6$ \\
Glycogen & 8.54 & $0.3-11.4(103)$ & $1.14-12.19$ \\
\hline
\end{tabular}

Enzyme measurements in iu/g wet weight made on muscle extracts as described in the text. Glycogen measurements are shown in $\mathrm{mg} / \mathrm{g}$ wet weight. The patient's results are a mean of three separate determinations. The total observed range of control groups of healthy subjects ( $N$ is the number of cases) and of nine patients with muscular dystrophy are shown for comparison. ND = no activity detected.
Table 2 Conversion of $\left({ }^{14} \mathrm{C}\right)$-substrates to $\left({ }^{14} \mathrm{C}\right)-\mathrm{CO}_{2}$ by fresh fibre bundles

\begin{tabular}{lrc}
\hline Substrate & Patient & Normal range \\
\hline $7.5 \mathrm{mM}$ glucose & 15.3 & $25-340$ \\
$6.9 \mathrm{mM}$ fructose & 634.6 & $18-280$ \\
$1.9 \mathrm{mM}$ palmitate & 44.1 & $24-550$ \\
$4.5 \mathrm{mM}$ butanoate & 3296.8 & $1000-11,560$ \\
$45.5 \mathrm{mM}$ 3 hydroxybutanoate & 3017.7 & $2000-5470$ \\
$6.5 \mathrm{mM}$ glucose-6-phosphate & 123.8 & $23-1519$ \\
\hline
\end{tabular}

Production of $\left({ }^{14} \mathrm{C}\right)-\mathrm{CO}_{2}$ by fresh muscle bundles in $\mathrm{nmol} / \mathrm{g}$ wet weight/hour. The total observed range of 13 healthy control subjects is shown for comparison.

when the muscle extract concentrations were as high as $400 \mathrm{mg}$ wet weight $/ \mathrm{ml}$ in the reaction cup and a 10 fold increase in instrument sensitivity was used. The glucose concentration was $5 \times 10^{-4} \mathrm{M}$, which is the correct order of magnitude for $\mathrm{HKII}^{1}$ and is the concentration at which $\mathrm{HK}$ is measured in all our muscle biopsy samples. Further investigation revealed a fructose phosphorylation mechanism with a high specific activity $(0.554 \mathrm{iu} / \mathrm{g})$ equivalent to the mean $\mathrm{HK}$ activity in the control muscle population (table 1). Fructose phosphorylation in normal muscle occurs to a limited extent with a mean specific activity of $0.05 \mathrm{iu} / \mathrm{g}$ and therefore our patient's muscle had 10 times the fructose phosphorylating capacity of normal tissues.

Because of the ability of muscle undergoing dystrophic change to shunt glucose to fructose via sorbitol dehydrogenase (the polyol pathway) ${ }^{1620}$ and then further metabolise this via abnormally active KHK and fructose-1-phosphate splitting aldolase, ${ }^{7}$ the KHK activity in this muscle was assayed (table 1) and shown to be present only at the low levels seen in normal muscle.

\section{Incubation experiments}

Incubation of muscle fibre bundles with radiotracer fuels also indicated a decreased ability to handle glucose in this patient's muscle (table 2), while showing an increased flux of fructose to $\mathrm{CO}_{2}$. The rate of utilisation and conversion to $\mathrm{CO}_{2}$ of the long (palmitate) and short (butanoate) chain fatty acids and the ketone (3-hydroxybutanoate) indicate that impaired glucose processing is not due to a fault in mitochondrial function. Table 3 which shows the con-

Table 3 Muscle lactate levels

\begin{tabular}{lcc}
\hline Substrate & Patient & Normal range \\
\hline $7.5 \mathrm{mM}$ glucose & 3.14 & $15-50$ \\
$6.9 \mathrm{mM}$ fructose & 10.25 & $5-29$ \\
$6.5 \mathrm{mM}$ glucose-6-phosphate & 22.72 & $10-44$ \\
\hline
\end{tabular}

Lactate levels ( $\mathrm{nmol} / \mathrm{g}$ wet weight) in incubation media in Warburg flasks after removal of fibre bundles for glycogen determinations. The total observed range of 13 healthy control subjects is shown for comparison. 
Table 4 Muscle sorbitol levels

\begin{tabular}{lll}
\hline Substrate & Patient & Normal range \\
\hline Preincubation & 2.14 & $0.07-0.25$ \\
$7.5 \mathrm{mM}$ glucose & 4.17 & $0.01-0.38$ \\
$6.9 \mathrm{mM}$ fructose & 2.71 & $0.01-0.38$ \\
$6.5 \mathrm{mM}$ glucose-6-phosphate & 3.35 & $0.02-0.47$ \\
\hline
\end{tabular}

Sorbitol levels (nmol/g wet weight) in incubation media in Warburg flasks after removal of fibre bundles for glycogen determinations. The total observed range of 13 healthy control subjects is shown for comparison.

version of substrate fuels to lactate, indicates some inability of this muscle to process glucose via anaerobic metabolism, compared with the other carbohydrate fuels included in the incubation batch. The fact that glucose-6-phosphate is metabolised normally to both $\mathrm{CO}_{2}$ (table 2) and lactate (table 3) indicates that glycolysis distal to hexokinase is normal. Table 4 shows that the preincubation concentration

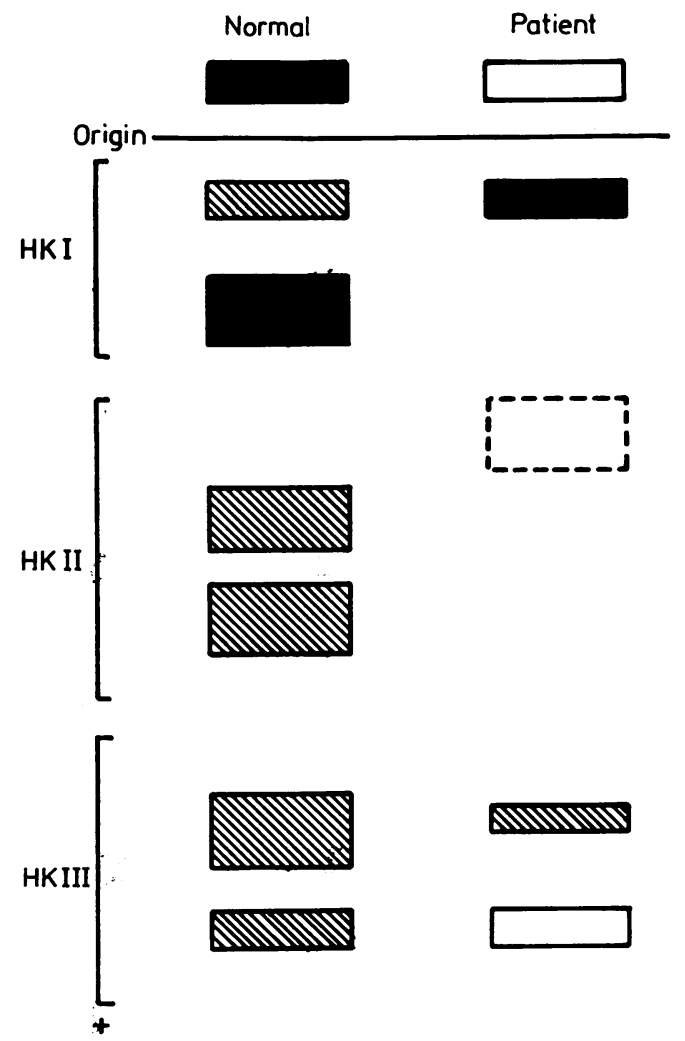

Fig 2 Diagram of muscle hexokinase isoenzyme electrophoresis in healthy subjects and in the patient. Electrophoretic techniques are described in the text. The degree of activity is represented by the amount of shading. The diagrams are derived from control muscle from eleven healthy subjects and three separate homogenates of the patient's muscle. of sorbitol was approximately 10 times the upper normal range, indicating the interconversion of glucose and fructose via the polyol pathway. Incubation studies showed similar increases in sorbitol concentration.

\section{Electrophoresis}

Electrophoresis of soluble extracts of muscle (fig 2) illustrates three anomalies in the pattern obtained from this patient. Most significant is the abnormally migrating band in the region of HKII which ran slower than in normal extracts and stained only faintly at all three glucose concentrations. Secondly the larger HKI band seen in the normal muscle electrophoretogram is missing, and the smaller slower band stains more densely. Thirdly in the HKIII region the normal pattern of two moderately stained bands is replaced by one narrow moderately stained band and one faintly stained one.

\section{Discussion}

The muscle from this patient exhibits an inability to phosphorylate glucose at the normal concentration $\left(10^{-4} \mathrm{M}\right)$ for HKII. This block would be so fundamental as to halt glucose metabolism completely. However, his relatively mild symptoms suggest that this is not so and that some form of metabolic com- $\triangle$ pensation is taking place. Our investigation suggests that there is a by-pass system in which fructose iso phosphorylated to fructose-6-phosphate, which itselff can then proceed along the usual glycolytic pathway Consistent with this hypothesis, incubation experiments have shown both an increased flux of fructose to $\mathrm{CO}_{2}$ and a normal flux to lactate, while glucose metabolism in these same experiments is at rates lower than expected for normal muscle. Furthermore, enzyme activity assays have shown a greatly increased capacity for fructose phosphorylation to fructose-6phosphate. Higher than normal levels of sorbitol in the muscle are also consistent with our hypothesis that glucose is converted to fructose before being further metabolised.

In studies on muscle from Duchenne muscular dystrophy patients the alteration in glucose metabolism favours fructose to fructose-1-phosphate formation. The subsequent metabolic splitting of this molecule by aldolase only yields one potential energy generating moiety and one free glyceraldelyde. This abnormal pathway severely depletes the supply of energy for muscle work and increases lipogenesis. In our patient however, a situation can be envisaged where the rate of glycolysis is slowed down by the need to convert available glucose to fructose before further metabolic processing can take place, but the net yield in energy is unaltered. The low level of blood fructose 
is not sufficient to provide the substrate for the compensatory mechanism. Therefore situations might arise, for example during long or strenuous exercise, when energy demand will exceed the rate at which it can be supplied leading to muscle cell damage and the associated symptoms. The "late rise" in the lactate level during the ischaemic exercise test may reflect this glucose reprocessing. A "late rise" in lactate, as seen in this patient, has also been observed by us in a number of cases with minor metabolic errors of glycolysis (unpublished data). However, glycogenolysis yields glucose-1-phosphate, which can convert to glucose-6phosphate and enter glycolysis normally and this would account for the normal peak lactate level, though the rate of lactate production was abnormal. Our patient was free of symptoms at rest, apart from occasional cramps, but on exertion particularly in the cold he developed pain and stiffness of his muscles, mainly in the lower limbs. In many respects his symptoms are similar to those of other disorders of muscle carbohydrate metabolism such as type V Glycogenosis (myophosphorylase deficiency) or type VII Glycogenosis (phosphofructokinase deficiency).

Although electrophoretic abnormalities have been shown in all HK regions, it is the abnormality of HKII that is likely to be responsible for the metabolic defect because HKII is the major muscle isoenzyme. The slow HKII band on the electrophoretogram which stained weakly for HK activity at all three glucose concentrations suggests that the protein is not absent but is in some way altered in structure leading to slower electrophoretic migration. The nature of this alteration may have caused the conformation of the protein's active site to be changed allowing fructose to bind in preference to glucose, leading to the high fructokinase activity. The fact that other body tissues normally have the same HKII electrophoretic mobility as muscle indicates that our results are not due to contamination of the muscle specimens. These patterns have not been seen in studies on muscle from other forms of muscle disease where HK isoenzymes have been examined by electrophoresis. ${ }^{8,21}$ Indeed only the X-linked muscular dystrophies show an electrophoretic abnormality in HKII which does not correspond to that of our patient. This suggests that our findings are not merely the result of muscle damage or atrophy. Reports of families with altered kinetic properties of erythrocyte $\mathrm{HK}^{10-1319}$ suggest that metabolically abnormal forms of the enzyme may occur which are analogous to the abnormal HK in our patient's muscle.
We are grateful to Dr RC Hughes for permission to report his patient and to Dr M Carey for reporting the histopathology.

\section{References}

1 Katzen HM, Schimke RT. Multiple forms of hexokinase in the rat: tissue distribution, age dependency and properties. Proc Natl Acad Sci USA 1965;54:1218-25.

2 Crane RK. Hexokinases and pentokinases. In: The Enzymes 2nd ed. Vol 6 Boyer PD, Lardy H, Myrback K eds) New York: Academy Press 1962. 47-66.

3 Grossbard L, Schimke RT. Multiple hexokinases of rat tissues. Purification and comparison of soluble forms. $J$ Biol Chem 1966;241:3546-60.

4 Strickland JM, Ellis DA. Isoenzymes of hexokinase in human muscular dystrophy. Nature 1975;253:464-6.

5 Sillero MAG, Sillero A, Sols A. Enzymes involved in fructose metabolism in liver and the glyceraldehyde metabolic crossroads. Eur J Biochem 1969;10:345-50.

6 Woods HF, Eggleston LV, Krebs HA. The cause of hepatic accumulation of fructose-1-phosphate on fructose loading. Biochem J 1970;119:501-10.

7 Ellis DA, Poulton KR, Tye JE. A fructolytic pathway in Duchenne muscular dystrophy. $J$ Neurosurg Neurol Psychiatry (in press).

8 Ellis DA, Strickland JM, Tye JE. Human hexokinase isoenzymes of muscle in health and disease. Biochem Soc Trans 1976;4: 1054-6.

9 Keitt AS. Haemolytic anaemia with impaired hexokinase activity. J Clin Invest 1969;48:1997-2007.

10 Moser K, Ciresa M, Schwarameir J. Hexokinasemangel bei hamolysticher Anamie. Med Welt 1970;46:1977-81.

11 Necheles TF, Rai US, Cameron D. Congenital nonspherocytic haemolytic anaemia associated with an unusual erythrocyte hexokinase abnormality. J Lab Clin Med 1979;76:593-8.

12 Siimes MA. Hexokinase deficiency in RBCs: a new variant in five members of a Finnish family. Scand J Haematol 1979;22: 214-8.

13 Magnani M, Stocchi V, Canestrai F, et al. Human erythrocyte hexokinase deficiency. A new variant with abnormal kinetic properties. Br J Haematol 1985;61:41-50.

14 McArdle B. Myopathy due to a deficit in muscle glycogen breakdown. Clin Sci 1951:10:13-33.

15 Umbriet WW, Burris RH, Stauffer JF. Manometric and Biochemical Techniques, 5th ed. Minneapolis: Burgess. 1972. 146.

16 Ellis DA, Strickland JM, Eccleston JF. The direct interconversion of glucose and fructose in human skeletal muscle with special reference to childhood muscular dystrophy. Clin Sci 1973;44:321-36.

17 Roehrigka KL, Allread JB. Direct enzymatic procedure for the determination of liver glycogen. Anal Biochem 1974;58:412-21.

18 Bergmeyer HU. Methods of Enzymatic Analysis. New York: Academy Press 1977.

19 Katzen HM, Soderman DD, Wiley CE. Multiple forms of hexokinase. J Biol Chem 1970;245:4081-96.

20 Ellis DA, Strickland JM. The effects of 3,3 tetramethylene glutaric acid on fructose formed from glucose by healthy and diseased human skeletal muscle preparations. Biochem Soc Trans 1974;2:131-3.

21 Munsat, TL. A standardised forearm ischaemic exercise test. Neurology 1970;20:1171-8. 